\title{
THE EFFECT OF PIR-9 COMPOUND ON MARKERS OF APOPTOSIS IN EXPERIMENTAL FOCAL CEREBRAL ISCHEMIA IN RATS
}

\section{A.V. Voronkov', N.B. Shabanova', M.P. Voronkova', T.A. Lysenko ${ }^{1}$, A.V. Arlt ${ }^{1}$, E.E. Zatsepina ${ }^{1}$}

\author{
${ }^{1}$ Pyatigorsk Medical and Pharmaceutical Institute - branch of Volgograd \\ State Medical University, 11, Kalinin ave., Pyatigorsk, Russia, 357532 \\ ${ }^{2}$ The Volgograd State Medical University, area of Fallen fighters, 1, \\ Volgograd, Russia, 400131
}

ABSTRACT - A study to assess the effect of a new pyrimidine derivative (PIR- 9 at a dose of $50 \mathrm{mg} / \mathrm{kg}$ ) on apoptosis markers in experimental focal cerebral ischemia of the rat brain. It has been confirmed that the investigated compound PIR-9 contributes to a decrease in the concentration of TNF $\alpha$ by $34,36 \%(p<0,05)$ as compared to that in rats treated with a reference drug Cavinton $(3,2 \mathrm{mg} / \mathrm{kg})$ and has an effect comparable in effect to Gliatilin $(60 \mathrm{mg} / \mathrm{kg})$. The concentration of AIF in rats that received compound PIR-9 was $29,99 \%(\mathrm{p}<0,05)$ less than the group of negative control rats.

\section{INTRODUCTION}

It is known that cerebral ischemia triggers apoptosis - regulated neuronal death, the mechanisms of action of which are currently well studied [1]. Tumor necrosis factor - a pro-inflammatory cytokine that activates the extrinsic (caspase-dependent) pathways of apoptosis, AIF-a protein that triggers the mitochondrial (caspase-independent) pathways of apoptosis, blocking the main proapoptotic pathways, can be promoted by cerebroprotection [2,3]. A potential cerebroprotective activity of pyrimidine derivatives has been confirmed earlier [4], therefore the problem of the effect of these compounds on apoptosis markers is of great interest.

\section{Objective}

To study the effect of PIR-9 compound on markers of apoptosis in experimental focal cerebral ischemia in rats.

\section{MATERIALS AND METHODS}

The study was conducted in accordance with the "Guidelines for Preclinical Trials of Drug Products" ed. by A.N. Mironov (a 2012 edition.) [5]. The experiment was performed on 30 male Wistar rats $\mathrm{m}=220-240 \mathrm{~g}$, divided into 5 groups $(\mathrm{n}=6)$. Rats were kept on a standard vivarium diet, with a natural
Article history:

Received 30 March 2019

Received in revised form 6 April 2019

Accepted 7 April 2019

succession of light and darkness. The first group was represented by falsely operated rats (FO), the second one - by negative control animals (NC). The both groups received an intraperitoneal suspension of Tween- 80 in purified water. The third and fourth groups received reference drugs: Cavinton $(3,2 \mathrm{mg} / \mathrm{kg})$ and Gliatilin $(60 \mathrm{mg} / \mathrm{kg})$, respectively [6, 7]. The fifth group received the investigational pyrimidine derivative PIR-9 $(50 \mathrm{mg} / \mathrm{kg})$ [8]. The second and subsequent groups modeled focal cerebral ischemia, by occlusion of the left middle cerebral artery (under chloral hydrate anesthesia, $350 \mathrm{mg} / \mathrm{kg}$ ) $[9,10]$. All objects were injected intraperitoneally immediately after the surgery and then once daily for three days. The concentration of tumor necrosis factor (TNF $\alpha$ ) and apoptosis-inducing factor (AIF) was determined by enzyme-linked immunosorbent assay in brain homogenate using a Tecan Infinite F50 microplate reader. All findings were processed by means of variation statistics methods using the STATISTICA 6.0 software. The normality of distribution was assessed by the Shapiro-Wilk test. In the case of a normal distribution of the data, a parametric $t$-test was applied. In the case of abnormal distribution of the data, the statistical processing was performed using the Mann-Whitney U-test. The difference was considered significant at the significance level of more than $95 \%(\mathrm{p}<0,05)$.

\section{RESULTS AND DISCUSSION}

The concentration of TNF $\alpha$ in falsely operated animals was 19,62 $\pm 0,51 \mathrm{pg} / \mathrm{ml}$ (Fig. 1), while in rats with focal cerebral ischemia not subjected to pharmacotherapy, this indicator reached $67,13 \pm 1,70 \mathrm{pg} / \mathrm{ml}$, which, in turn, exceeded the value of the FO group by 3,42 times $(p<0,05)$. In the group of rats that were injected with cavinton, the level of TNF $\alpha$ was significantly reduced by $45,11 \%$ $(\mathrm{p}<0,05)$, compared with intraperitoneal administration of gliatilin, the identical value was $57,47 \%$ $(p<0,05)$ less in the negative control animals group. At the same time, statistically significant differences in this indicator between groups of rats treated with Cavinton and Gliatilin were noted. A tendency to a 
decrease in the concentration of tumor necrosis factor was also observed during the administration of the experimental compound PIR-9. The concentration of TNF $\alpha$ in the group of animals treated with PIR-9 was $24,19 \pm 1,22 \mathrm{pg} / \mathrm{ml}$, which is $63,97 \%(\mathrm{p}<0,05)$ and $34,36 \%(\mathrm{p}<0.05)$ was less values of rats not subject to therapy and treated with Cavinton, respectively.

In the group of FO rats, the AIF content was $4,08 \pm 0,24 \mathrm{ng} / \mathrm{ml}$. Occlusion of the left middle cerebral artery contributed to an increase in AIF concentration by 1,98 times $(\mathrm{p}<0,05)$ (Fig. 2$)$ in comparison with sham-operated animals and, as a result, activated AIFmediated cell death [3]. Intraperitoneal administration of the comparing drugs Cavinton and Gliatilin led to a decrease in the concentration of the factor inducing apoptosis in relatively untreated animals by $35,19 \%$ $(\mathrm{p}<0,05)$ and $38,41 \%(\mathrm{p}<0,05)$. A similar change was noted with the introduction of the experimental substance, for example, in individuals that were injected with compound PIR-9, the AIF concentration was $29,99 \%(\mathrm{p}<0,05)$ less relative to the group of untreated animals.

\section{REFERENCES}

1. Shlyakhto E.V., Barantsevich E.P., SHCherbak N.S., GAlagudza M.M. Molecular mechanisms of development of cerebral tolerance to ischemia. Part 1. Annals of the Russian academy of medical sciences. 2012;67(6):42-50. (In Russ.)

2. WU H. Y., WANG Y., HaN W. Effects of Acupuncture Stimulation on Dynamic Changes of Cerebral TNF- $\alpha$ and C-reaction Protein Levels in Cerebral Ischemiareperfusion Rats //Zhen ci yan jiu= Acupuncture research. - 2015. - Vol. 40, № 3. - P. 215-218.

3. Hu G., Wu Z., Yang F. [eT al.]. Ginsenoside Rd blocks AIF mitochondrio-nuclear translocation and NF- $\kappa$ B nuclear accumulation by inhibiting poly (ADPribose) polymerase-1 after focal cerebral ischemia in rats //Neurological Sciences. - 2013. - Vol. 34, № 12. - P. 2101-2106.

4. Voronkov A.V., Shabanova N.B., Kodonidi I.P., Shatalov I.S. Cerebroprotective activity of new derivatives of pirimidine-4-(1H)-one PIR-9 and PIR-10 in irreversible occlusion of the common carotid artery. Pharmacy \& Pharmacology. 2018;6(2):167-181. (In Russ.) DOI: 10.19163/2307-9266-2018-6-2-167-181

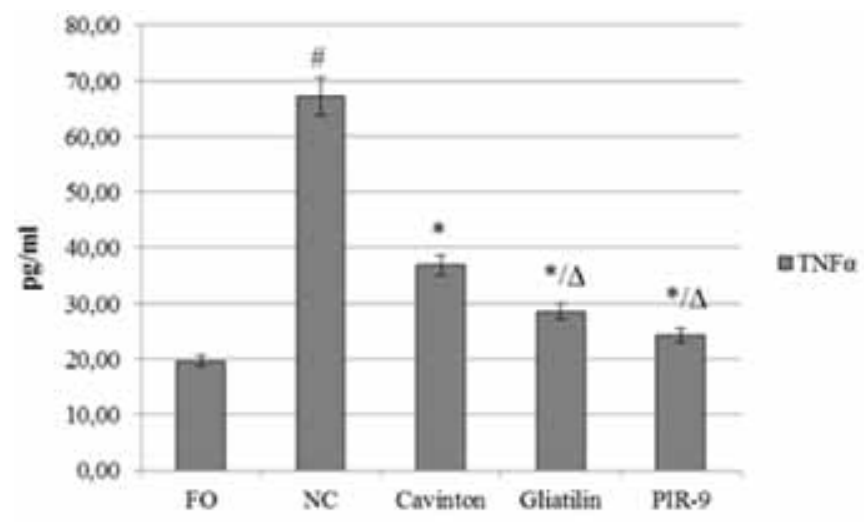

Fig. 1. Assessment of the effect of PIR-9 compound and the reference drugs on the concentration of tumor necrosis factor under conditions of focal cerebral ischemia in rats

Note: $F 0$ - false-operated rats; $N C$ — negative control rats; Cavinton — a group rats treated with Cavinton; Gliatilin — a group of rats receiving Gliatilin; PIR-9 — a group of rats treated with PIR-9; \# - statistically significant as compared to the FO rats $(p<0,05)$; * - statistically significant as compared to the NC rats $(p<0,05) ; \Delta$ — statistically significant as compared to rats treated with Cavinton $(p<0,05)$.

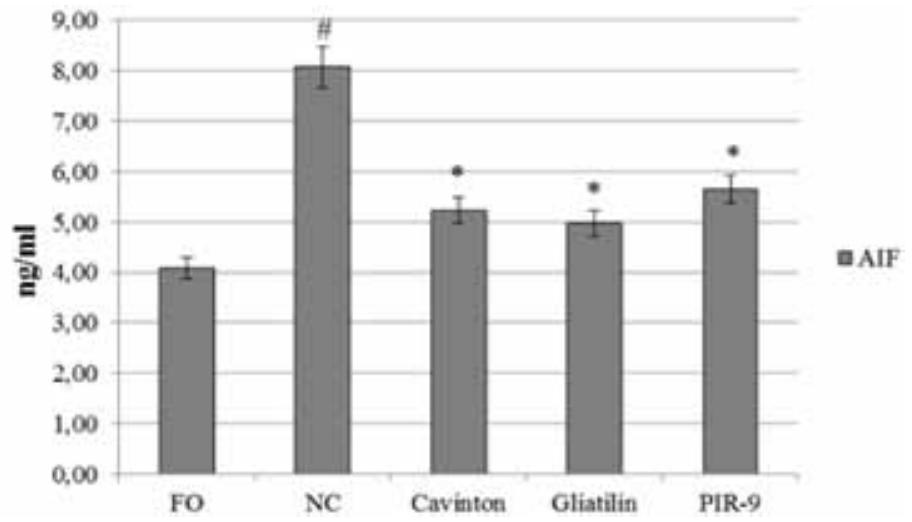

Fig. 2. Assessment of the effect of PIR-9 compound and the reference drugs on the concentration of apoptosis-inducing factor under conditions of focal cerebral ischemia in rats

Note: $\mathrm{FO}$ — false-operated rats; $N \mathrm{NC}$ - negative control rats; Cavinton — a group rats treated with Cavinton; Gliatilin — a group of rats receiving Gliatilin; PIR-9 — a group of rats treated with PIR-9; \# - statistically significant as compared to the FO rats $(p<0,05)$; * - statistically significant as compared to the $N$ C rats $(p<0,05)$.

\section{CONCLUSION}

In the experimentally simulated cerebrovascular insufficiency, a pyrimidine derivative (known under laboratory code PIR-9 reduced the concentration of apoptosis markers (TNF $\alpha$ and AIF) in animals, it is also essential that the effect was not inferior in its power to the comparison drug Gliatilin and superior to Cavinton.
5. Mironov A.N. The guidelines for preclinical studies of pharmaceuticals. Part one. - M.: Grif and K, 2012. - 944 p. (In Russ.)

6. Nazarova L.E., Dyakova I.N. Influence of ferulic acid on the necrosis zone resulting from occlusion of the middle cerebral artery //medical Bulletin of Bashkortostan 2011. No. 3. P. 133-135. (In Russ.)

7. Skoromets A., Melnikova E., Churilova I., SHMONIN A. Multifactorial neuroprotection in ischemic 
stroke (clinical and experimental study) //Doctor 2009. - № 2. - P. 26-30.

8. Voronkov A.V., Shabanova N.B., Voronkova M.P., LYSENKo T.A. Study of cerebrotropic dosedependent effect of pyrimidine derivative under pir-9 code against the background of experimental cerebral ischemia in rats.Pharmacy \& Pharmacology. 2018;6(6):548-567. (In Russ.) DOI: 10.19163/23079266-2018-6-6-548-567

9. Trofimenko A.I., Kade A.A., Lebedev V.P., Zanin S.A., Myasnikova V.V. Modeling cerebral ischemia by coagulation of the middle cerebral artery in rats / Fundamental research - 2012. - №2. P. $215-218$.

10. Manual of stroke models in rats / ed. by Y. WangFischer. - [S. 1.] : CRC Press : Taylor\& Francis Group, 2009. - XIII, $332 \mathrm{p}$. 